\title{
Zirconia stimulates ECM-remodeling as a prerequisite to pre- osteoblast adhesion/proliferation by possible interference with cellular anchorage
}

\author{
Celio J. da Costa Fernandes ${ }^{1} \cdot$ Marcel Rodrigues Ferreira ${ }^{1} \cdot$ Fábio J. B. Bezerra ${ }^{1}$ ' Willian F. Zambuzzi $\mathbb{i}^{1}$
}

Received: 22 August 2017 / Accepted: 5 March 2018 / Published online: 26 March 2018

(c) Springer Science+Business Media, LLC, part of Springer Nature 2018

\begin{abstract}
The biological response to zirconia $\left(\mathrm{ZrO}_{2}\right)$ is not completely understood, which prompted us to address its effect on preosteoblastic cells in both direct and indirect manner. Our results showed that zirconia triggers important intracellular signaling mainly by governing survival signals which leads to cell adhesion and proliferation by modulating signaling cascade responsible for dynamic cytoskeleton rearrangement, as observed by fluorescence microscopy. The phosphorylations of Focal Adhesion Kinase (FAK) and Rac1 decreased in response to $\mathrm{ZrO}_{2}$ enriched medium. This corroborates the result of the crystal violet assay, which indicated a significant decrease of pre-osteoblast adhesion in responding to $\mathrm{ZrO}_{2}$ enriched medium. However, we credit this decrease on pre-osteoblast adhesion to the need to govern intracellular repertory of intracellular pathways involved with cell cycle progression, because we found a significant up-phosphorylation of Mitogen-Activated Protein Kinase (MAPK)-p38 and Cyclin-dependent kinase 2 (CDK2), while p15 (a cell cycle suppressor) decreased. Importantly, Protein phosphatase 2 A (PP2A) activity decreased, guaranteeing the significant up-phosphorylation of MAPK - $\mathrm{p} 38$ in response to $\mathrm{ZrO}_{2}$ enriched medium. Complementarily, there was a regulation of Matrix Metalloproteinases (MMPs) in response to Zirconia and this remodeling could affect cell phenotype by interfering on cell anchorage. Altogether, our results show a repertory of signaling molecules, which suggests that ECM remodel as a pre-requisite to preosteoblast phenotype by affecting their anchoring in responding to zirconia.
\end{abstract}

\section{Introduction}

Bone is a highly dynamic tissue capable of remodeling itself throughout life [1]. When damaged, its physiology allows regenerating of minor lesions. On the other hand, in cases of critical-sized bone defects, biomaterials must be used to guide tissue regeneration [2,3]. Ideally, a biomaterial should be able to recruit osteoprogenitor cells into the lesion region, subsequently stimulating their proliferation and consequent differentiation by well-orchestrated signaling involving cells and trophic molecules. Among the several properties to be considered for successful osseointegration, the biomaterial needs to have adequate physical-chemical

Willian F. Zambuzzi

wzambuzzi@ibb.unesp.br

1 Bioassays and Cell Dynamics Lab, Dept. of Chemistry and Biochemistry, Bioscience Institute, Universidade Estadual Paulista UNESP, Botucatu, Sao Paulo, Brazil composition and bioactivity on its surface [4]. Thus, titanium alloys are widely used for bone tissue regeneration, but in the last decade there has been growing interest in understanding the behavior of bioceramic materials as an implantable material, such as zirconium dioxide $\left(\mathrm{ZrO}_{2}\right)$, also known as zirconia [5, 6].

Beyond its mechanical properties, zirconia devices have emerged as an alternative mainly due to aesthetic aspects; however, it has other important clinical properties [7]. Initially, zirconia was used in artificial dental crowns and abutments of implants, due to its very interesting physical and mechanical properties. Zirconia has low thermal conductivity and can withstand flexural stresses in the order of $1000 \mathrm{MPa}$ and $2000 \mathrm{MPa}$ of effective compression. Due to its great strength, zirconia is known as "ceramic steel", and is considered the second strongest material, only behind diamond [8, 9]. Recently, zirconia has been used as for implants because of its biological response such as adequate biocompatibility with bone tissue cells. Many studies have demonstrated that zircon surfaces do not produce any cytotoxic effects by exploring in in vitro technologies, or 
any kind of systemic infection when implanted in mice or rabbits [8-10]. In addition, zirconia has been shown to be capable of inducing the proliferation of pre-osteoblast, as well as increasing the gene expression of type I collagen and osteopontin [10]. Although zirconia dental implants are receiving increasing attention, no papers have reported the molecular mechanisms governing cell adhesion on its surface.

Animal models are widely used in the research that evaluates biological behavior of novel biomaterials. Over the last decade, our group has proposed the use of in vitro approaches by diagnostic intracellular signal transduction mechanisms, which have been proposed as important tools to predict biomaterial-cell interactions and are considered alternative approaches that reduce the use of experimental animals in biomedical materials research. To this end, biomarkers of cell metabolism, such as Focal Adhesion Kinase (FAK), Src, Paxilin, and Cofilin, among other kinases and phosphatases, appear as alternative tools to evaluate the biocompatibility of biomedical materials. In this work, we demonstrated for the first time part of the molecular mechanism involved with the biological response to zirconia, revealing a repertory of signaling molecules able to propose Extracellular Matrix (ECM) remodeling as a prerequisite to contribute to pre-osteoblast phenotype by affecting their anchorage.

\section{Material and methods}

\subsection{Cell culture}

Mouse pre-osteoblastic cells, MC3T3-E1 (subclone 4) (ATCC CRL-2593), were culture in $\alpha$ MEM supplemented with $10 \%$ of Fetal Bovine Serum (FBS) at $37^{\circ} \mathrm{C}$ and $5 \%$ $\mathrm{CO}_{2}$. For all experiments, cells were tripsinized at subconfluent passages when they were used.

\subsection{Zirconia propeties and cell viability assay}

For the cell viability assay, $\alpha \mathrm{MEM}$ was conditioned with zirconia (Alumina toughened Zirconia, composition: $76 \%$ $\left.\mathrm{ZrO}_{2}, 20 \% \mathrm{Al}_{2} \mathrm{O}_{3}, 4 \% \mathrm{YO}_{3}, \mathrm{ZrO}_{2}\right)$ discs $(0.01 \mathrm{mg} / \mathrm{mL}$, with $0.6 \mathrm{~cm}$ diameter) for $24 \mathrm{~h}$ and then the $\mathrm{ZrO}_{2}$ enriched medium was used to treat the pre-osteoblast for additional $24 \mathrm{~h}$ in semiconfluence (around $100 \times 10^{3}$ cells $/ \mathrm{ml}$ ). Thereafter, the medium was replaced by a vital dye MTT (1 mg/ $\mathrm{mL}$ ) [11] and incubated for an additional $4 \mathrm{~h}$. Then, the MTT medium was removed and the blue precipitate dye diluted in $100 \mu \mathrm{L} /$ well of absolute alcohol. In the end, the cell viability was estimated by measuring the absorbance in a microplate reader (SYNERGY-HTX multi-mode reader, Biotek, USA) at $570 \mathrm{~nm}$ wavelength.

\subsection{Cell adhesion assay}

$\mathrm{ZrO}_{2}$ enriched medium was also used to measure its influence on cell adhesion by using crystal violet as the approach (Rossi et al., 2017; Bezerra et al., 2017). Previously, the cells were challenged with $\mathrm{ZrO}_{2}$ enriched medium up to $24 \mathrm{~h}$ when the cells were trypsinized, and reseeded on 96well microplate at $100 \times 10^{3}$ cells $/ \mathrm{ml}$. A control group was considered by reseeding the cells with conventional cell culture conditions. After $24 \mathrm{~h}$ of seeding, cell adhesion was estimated by incorporating the crystal violet, as detailed somewhere. The absorbance was measured at $540 \mathrm{~nm}$ using a microplate reader (SYNERGY-HTX multi-mode reader, Biotek, USA), which was used to estimate the profile of adherent cells.

\subsection{Scanning electron microscopy (SEM)}

Pre-osteoblasts were plated onto zirconia discs at the density of $50 \times 10^{3}$ cells/disc, and after $24 \mathrm{~h}$ were fixed with $2.5 \%$ of glutaraldehyde in $0.1 \mathrm{M}$ phosphate buffer $\mathrm{pH} 7.3$ for $24 \mathrm{~h}$. After the dehydration steps, they were sent to the critical point, assembled in the "stubs" and then metallized. The SEM analyses were performed on a Quanta 200-FEI Company scanning electron microscope at an accelerating voltage of $12.5 \mathrm{kV}$.

\subsection{Western blotting (WB)}

Semiconfluent pre-osteoblasts were treated in $\mathrm{ZrO}_{2}$ enriched medium up to $24 \mathrm{~h}$, then they were lysed on ice for $2 \mathrm{~h}$ with Lysis Cocktail (50 mM Tris [tris(hydroxymethyl) aminomethane]-HCl [pH 7.4], $1 \%$ Tween 20, $0.25 \%$ sodium deoxycholate, $150 \mathrm{mM} \mathrm{NaCl}, 1 \mathrm{mM}$ EGTA (ethylene glycol tetraacetic acid), $1 \mathrm{mM} \mathrm{O}$-Vanadate, $1 \mathrm{mM} \mathrm{NaF}$, and protease inhibitors $[1 \mu \mathrm{g} / \mathrm{mL}$ aprotinin, $10 \mu \mathrm{g} / \mathrm{mL}$ leupeptin, and $1 \mathrm{mM}$ 4-(2-amino-ethyl)-benzolsulfonyl-fluoridhydrochloride]) to obtain the pool of protein. After being lysed, the samples were sonicated (1 pulse per second; SONICS Vibra-Cell, USA) and maintained for an additional $1 \mathrm{~h}$ on ice. The protein extracts were clarified and the protein concentration determined by the Lowry method [12]. Proteins extracts were resolved by SDS-PAGE (10 or 12\%) and transferred to PVDF membranes (Bio-Rad, Hercules, CA, USA). Immediately, the membranes were blocked with either $1 \%$ fat-free dried milk or bovine serum albumin $(2.5 \%)$ in Tris-buffered saline (TBS)-Tween $20(0.05 \%)$ and incubated overnight at $4{ }^{\circ} \mathrm{C}$ with appropriate primary antibody at 1:1000 dilutions overnight. After washing in TBS-Tween $20(0.05 \%)$, the membranes were incubated with horseradish peroxidase-conjugated anti-rabbit, antigoat, or anti-mouse IgGs secondary antibodies, at 1:5000 dilutions, in blocking buffer for $1 \mathrm{~h}$ at room temperature. 
Thereafter, Enhance Chemiluminescence (ECL, Pierce, USA) was used to detect the bands.

\subsection{RT-qPCR}

To collect samples for qPCR, the pre-osteoblasts were plated in a petri dish (100 $\mathrm{mm}$ diameter) for adhesion. At semiconfluence, they were treated with $\mathrm{ZrO}_{2}$ enriched medium (indirect model) or grown on zirconia (direct model) for $24 \mathrm{~h}$, when the culture medium was removed and TriZOL and treated with DNase I (Invitrogen, Carlsband, CA, USA). cDNA synthesis was performed with High Capacity cDNA Reverse Transcription Kit (Applied Biosystems, Foster City, CA) according to the manufacturer's instructions. qPCR was carried out in a total of $10 \mu \mathrm{l}$, containing PowerU ${ }^{\mathrm{TM}}$ SYBR ${ }^{\mathrm{TM}}$ Green Master Mix $2 \times(5$ $\mu \mathrm{l})($ Applied Biosystems, Foster City, CA), $0.4 \mu \mathrm{M}$ of each primer, 50 ng of cDNA and nuclease free $\mathrm{H}_{2} \mathrm{O}$. Fold changes were analyzed using the comparative $\mathrm{Ct}$ method $(\Delta \Delta \mathrm{Ct})$ normalizing to GAPDH expression and comparing to static conditions as a reference. $\mathrm{qPCR}$ was performed using a QuantStudio 3 Real-Time PCR System to assess changes in mRNA expression in the genes (Table 1).

\subsection{Matrix metalloproteinase activities}

After identifying the involvement of matrix remodeling marker gene in response to $\mathrm{ZrO}_{2}$ enriched medium, we decided to investigate whether there were MMP activities by exploring the Zymography approach. The pre-osteoblast cultures were treated as detailed previously when the conditioned medium was collected. The gelatinolytic activities of the samples were evaluated by resolving the sample from cell culture supernatants, and SDS-PAGE was performed on

Table 1 Expression primers sequences and PCR cycle conditions

\begin{tabular}{|c|c|c|c|}
\hline Gene & Primer & $5^{\prime}-3^{\prime}$ Sequence & Reactions Condition \\
\hline \multirow[t]{2}{*}{$M M P 2$} & Forward & AACTTTGAGAAGGATGGCAAGT & $95^{\circ} \mathrm{C}-3 \mathrm{~s} ; 55^{\circ} \mathrm{C}-8 \mathrm{~s} ; 72^{\circ} \mathrm{C}-20 \mathrm{~s}$ \\
\hline & Reverse & TGCCACCCATGGTAAACAA & \\
\hline \multirow[t]{2}{*}{$M M P 9$} & Forward & TGTGCCCTGGAACTCACACGAC & $95^{\circ} \mathrm{C}-3 \mathrm{~s} ; 55^{\circ} \mathrm{C}-8 \mathrm{~s} ; 72^{\circ} \mathrm{C}-20 \mathrm{~s}$ \\
\hline & Reverse & ACGTCGTCCACCTGGTTCACCT & \\
\hline \multirow[t]{2}{*}{ TIMP1 } & Forward & ATCCTCTTGTTGCTATCACTG & $95^{\circ} \mathrm{C}-5 \mathrm{~s} ; 56^{\circ} \mathrm{C}-10 \mathrm{~s} ; 72^{\circ} \mathrm{C}-15 \mathrm{~s}$ \\
\hline & Reverse & GGTCTCGTTGATTTCTGGG & \\
\hline \multirow[t]{2}{*}{ TIMP2 } & Forward & GCAACAGGCGTTTTGCAATG & $95^{\circ} \mathrm{C}-3 \mathrm{~s} ; 55^{\circ} \mathrm{C}-8 \mathrm{~s} ; 72^{\circ} \mathrm{C}-20 \mathrm{~s}$ \\
\hline & Reverse & CGGAATCCACCTCCTTCTCG & \\
\hline \multirow[t]{2}{*}{$R E C K$} & Forward & CCTCAGTGAGCACAGTTCAGA & $95^{\circ} \mathrm{C}-3 \mathrm{~s} ; 55^{\circ} \mathrm{C}-8 \mathrm{~s} ; 72^{\circ} \mathrm{C}-20 \mathrm{~s}$ \\
\hline & Reverse & CCTGTGGCATCCACGAAACT & \\
\hline \multirow[t]{2}{*}{ Integrin- $\beta 1$} & Forward & CTGATTGGCTGGAGGAATGT & $95^{\circ} \mathrm{C}-3 \mathrm{~s} ; 60^{\circ} \mathrm{C}-8 \mathrm{~s} ; 72^{\circ} \mathrm{C}-20 \mathrm{~s}$ \\
\hline & Reverse & TGAGCAATTGAAGGATAATCATAG & \\
\hline \multirow[t]{2}{*}{ Src } & Forward & TCGTGAGGGAGAGTGAGAC & $95^{\circ} \mathrm{C}-3 \mathrm{~s} ; 60^{\circ} \mathrm{C}-8 \mathrm{~s} ; 72^{\circ} \mathrm{C}-20 \mathrm{~s}$ \\
\hline & Reverse & GCGGGAGGTGATGTAGAAAC & \\
\hline \multirow[t]{2}{*}{$P P 2 A$} & Forward & ATGGGCCTCTCTCCCATTCT & $95^{\circ} \mathrm{C}-3 \mathrm{~s} ; 60^{\circ} \mathrm{C}-8 \mathrm{~s} ; 72^{\circ} \mathrm{C}-20 \mathrm{~s}$ \\
\hline & Reverse & CATGCACAGGGAGTGACAGT & \\
\hline \multirow[t]{2}{*}{$F A K$} & Forward & TCCACCAAAGAAACCACCTC & $95^{\circ} \mathrm{C}-3 \mathrm{~s} ; 60^{\circ} \mathrm{C}-8 \mathrm{~s} ; 72^{\circ} \mathrm{C}-20 \mathrm{~s}$ \\
\hline & Reverse & ACGGCTTGACACCCTCATT & \\
\hline \multirow[t]{2}{*}{ Cofilin } & Forward & CAGACAAGGACTGCCGCTAT & $95^{\circ} \mathrm{C}-3 \mathrm{~s} ; 60^{\circ} \mathrm{C}-8 \mathrm{~s} ; 72^{\circ} \mathrm{C}-20 \mathrm{~s}$ \\
\hline & Reverse & TTGCTCTTGAGGGGTGCATT & \\
\hline \multirow[t]{2}{*}{$C D K 2$} & Forward & TACCCAGTACTGCCATCCGA & $95^{\circ} \mathrm{C}-3 \mathrm{~s} ; 60^{\circ} \mathrm{C}-8 \mathrm{~s} ; 72^{\circ} \mathrm{C}-20 \mathrm{~s}$ \\
\hline & Reverse & CGGGTCACCATTTCAGCAAA & \\
\hline \multirow[t]{2}{*}{$C D K 4$} & Forward & TCGATATGAACCCGTGGCTG & $95^{\circ} \mathrm{C}-3 \mathrm{~s} ; 60^{\circ} \mathrm{C}-8 \mathrm{~s} ; 72^{\circ} \mathrm{C}-20 \mathrm{~s}$ \\
\hline & Reverse & TTCTCACTCTGCGTCGCTTT & \\
\hline \multirow[t]{2}{*}{ CDK6 } & Forward & CGCCGATCAGCAGTATGAGT & $95^{\circ} \mathrm{C}-3 \mathrm{~s} ; 60^{\circ} \mathrm{C}-8 \mathrm{~s} ; 72^{\circ} \mathrm{C}-20 \mathrm{~s}$ \\
\hline & Reverse & GCCGGGCTCTGGAACTTTAT & \\
\hline \multirow[t]{2}{*}{$P 21$} & Forward & CGCCGATCAGCAGTATGAGT & $95^{\circ} \mathrm{C}-3 \mathrm{~s} ; 60^{\circ} \mathrm{C}-8 \mathrm{~s} ; 72^{\circ} \mathrm{C}-20 \mathrm{~s}$ \\
\hline & Reverse & GCCGGGCTCTGGAACTTTAT & \\
\hline \multirow[t]{2}{*}{ GAPDH } & Forward & AGGCCGGTGCTGAGTATGTC & $95^{\circ} \mathrm{C}-3 \mathrm{~s} ; 60^{\circ} \mathrm{C}-8 \mathrm{~s} ; 72^{\circ} \mathrm{C}-20 \mathrm{~s}$ \\
\hline & Reverse & TGCCTGCTTC ACCACCTTCT & \\
\hline
\end{tabular}


gels containing $0.1 \%$ gelatin and $10 \%$ polyacrylamide [13]. Samples, previously mixed with loading buffer (2\% SDS and $0.1 \%$ bromophenol blue), were electrophoresed under nonreducing conditions. After electrophoresis, gels were washed in 2\% Triton X-100 and immersed in buffer containing $50 \mathrm{mM}$ Tris- $\mathrm{HCl}(\mathrm{pH} 7.6), 200 \mathrm{mM} \mathrm{NaCl}$, and $10 \mathrm{mM} \mathrm{CaCl} 2$ for $18 \mathrm{~h}$ at $37^{\circ} \mathrm{C}$. The gels were stained with $0.5 \%$ Coomassie Blue G-250 in acetic acid/methanol/water $(1: 4: 5 \mathrm{vol} / \mathrm{vol} / \mathrm{vol})$ [14] and destained in acetic acid/ $\mathrm{methanol} /$ water $(1: 2: 7 \mathrm{vol} / \mathrm{vol} / \mathrm{vol})$.

\subsection{Statistical analysis}

The results were plotted as mean \pm standard deviation (SD) and significances were verified using One-Way ANOVA (non-parametric) with Tukey test powders. In this case, $p<0.05$ was considered statistically significant and $p<0.0001$ considered highly significant. For the statistical analysis, the groups were standardized by the percentage of control.

\section{Results}

\subsection{Zirconia compromises pre-osteoblast adhesion by down-regulating FAK and RAC1 activations}

To verify whether zirconia is able to modulate osteoblast performance, we explored 2 biological models: direct and indirect contact. For the direct model the cells were seeded on the zirconia, and for the indirect model, the zirconia was incubated in cell culture medium up to $24 \mathrm{~h}$ in order to enrich previously the medium $\left(\mathrm{ZrO}_{2}\right.$-enriched medium) to treat the cells, in agreement to ISO 10993:2016. First, we found that $\mathrm{ZrO}_{2}$-enriched medium influenced pre-osteoblast performance. Using violet crystal, it was verified that $\mathrm{ZrO}_{2}$ enriched medium decreased the cellular adhesion of preosteoblasts compared to the control (Fig. 1a). To understand this event, we investigated the balance of the crucial proteins involved with the intracellular cascade triggered upon integrin activation (signaling pathway proposed in Fig. 1b), culminating in cytoskeleton rearrangement; thus, B1-integrin, FAK, Rac1 and Cofilin were analyzed (Fig. 1c-j), while GADPH as used a housekeeping control.

The activation of FAK was analyzed by investigating its three possible phosphorylated residues, Y397 (Fig. 1c, e), Y576/577 (Fig. 1c, f), and Y925 (Fig. 1c, g), all involved with cell adhesion and governing cytoskeleton rearrangement culminating in the transitionally cofilin phosphorylation. Phosphorylations at residues Y576/577 and Y925 did not present any change, while the residue Y397 showed significant decrease $(p=0.0060)$ in response to $\mathrm{ZrO}_{2}$ enriched medium. Concomitantly, we also found an important effect on $\beta 1$-integrin expression (Fig. 1c, d), while Rac1 activation was down-modulated $(p=0.0001$; Fig. $1 \mathrm{~h}, \mathrm{i})$. For cytoskeleton-based cell adhesion, cofilin phosphorylation presented the same profile as the control (Fig. 1h, j). To validate this biological effect, we investigated the actin-based cytoskeleton rearrangement by using fluorescence microscopy and found that $\mathrm{ZrO}_{2}$ promotes significant changes in actin organization (Fig. 1k-p). As these large bundles of actin, called stress fibers, appear preferentially in response to $\mathrm{ZrO}_{2}$, our model provides a mechanism for stress fiber formation and stiffness sensing in $\mathrm{ZrO}_{2}$-responding cells.

Using a direct contact model, we later evaluated the morphological changes of pre-osteoblasts grown on the zirconia surface for $24 \mathrm{~h}$ using SEM, when adhered cells showed advanced spreading, indicating modulation of signaling pathways responsible for governing cytoskeleton rearrangement (Fig. 2a). In addition, we investigated expression of genes related with cell adaptation on the substrate and showed $\beta 1$-integrin (Fig. 2b) and Src (Fig. 2d) were significantly down-modulated, but $F A K$ (Fig. 2c), cofilin (Fig. 2e), and PP2A (Fig. 2f) were significantly upmodulated.

\subsection{Zirconia enhances survival signaling-related transducers}

First, we evaluated the cell viability of pre-osteoblast subjected to $\mathrm{ZrO}_{2}$ enriched medium by using classical MTT assay. Ferreira et al. using MTT estimated cell viability and proliferation [15]. Our results showed that $\mathrm{ZrO}_{2}$-enriched medium enhances pre-osteoblasts viability (Fig. 3a), which suggests an increased cell cycle. For a better understanding, the signaling pathway was addressed by evaluating proteinrelated cell cycle and survival signaling transducers. Thus, we evaluated the involvement of important signaling transducers for cell survival and found an important AKT requirement (Fig. 3b, c). In addition, mitogen-activated protein kinases (MAPKs) were significantly up-activated, as follows: p38 (Fig. 3d, e), ERK (Fig. 3f, g), and JNK (Fig. 3h, i). In order to evaluate whether those survival signaling culminate in proliferation fashion, we reported a significant increase of CDK2 phosphorylation (Fig. 3j, k), while p15 expression presented a slight down-regulation (Fig. 31, m). The balance on CDK2 and p15 is known to be involved in cell cycle progression. At this point, it seems the Ser/Thr phosphorylation balance is an important biomarker of zirconia-related response. Thus, we decided to investigate the potential involvement of PP2A, a Ser/Thr phosphatase able to hydrolyze phosphoryl moiety from phosphorylated Ser/Thr sites. Our results showed PP2A was significantly up-phosphorylated at Y307 $(p=0.0431)$ in response to $\mathrm{ZrO}_{2}$-enriched medium (Fig. 3n, o), indicating its inhibition. 

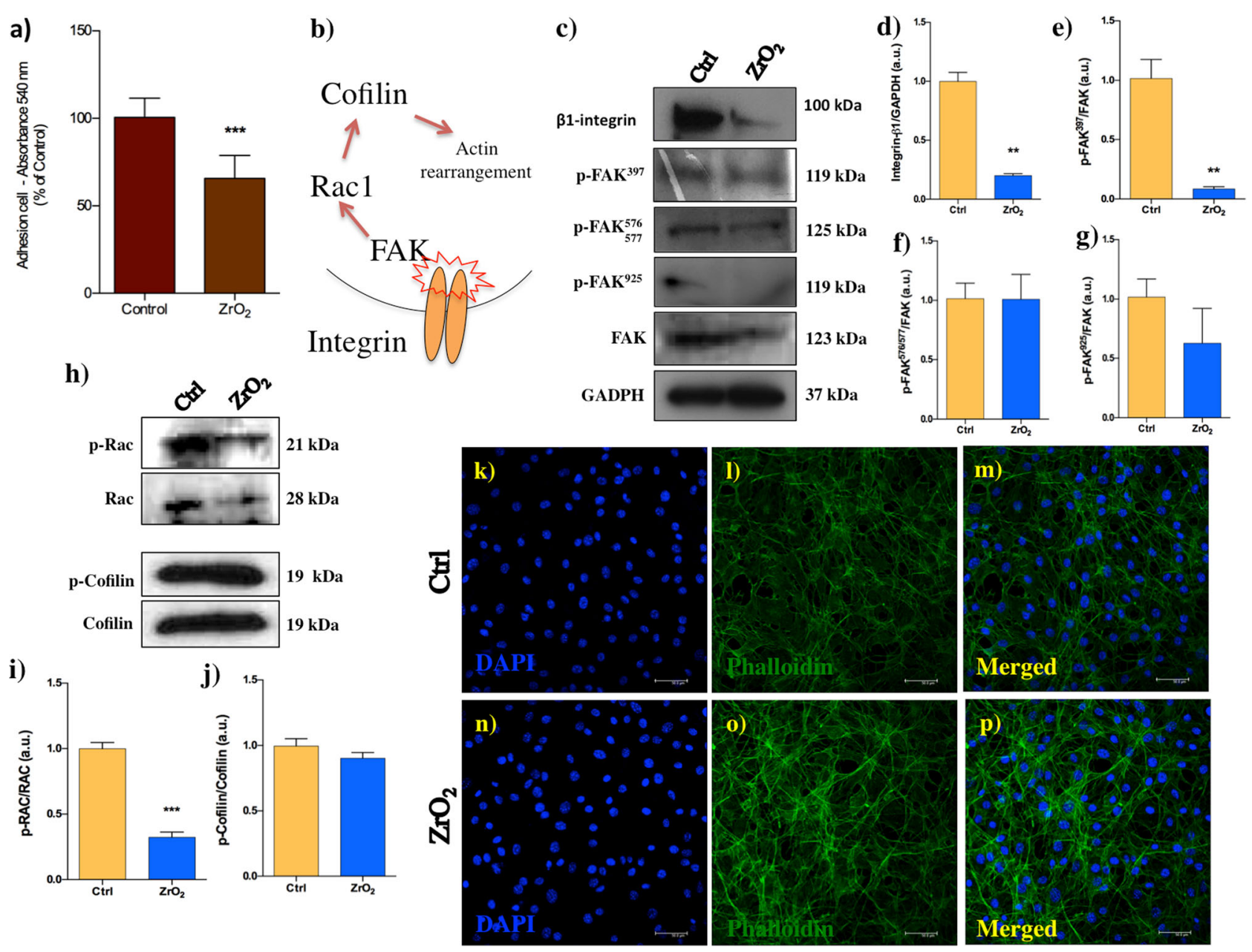

Fig. $1 \mathrm{ZrO}_{2}$ enriched medium modulates the activation of important proteins during the adhesion of pre-osteoblasts. a adhesion was evaluated when pre-osteoblasts were challenged with to $\mathrm{ZrO} 2$ enriched medium up to $24 \mathrm{~h}$. To understand the intracellular signaling responsible for governing the adhesion, we first proposed the general scheme presented in (b). The cascade of the activation involves FAK, Rac, and Cofilin upon integrin activation culminating in the cytoskeleton rearrangement and later governing cell adhesion. FAK was evaluated $\mathbf{c}-\mathbf{g}$, and it is possible to observe its phosphorylations at several residues (Y397, Y576/577, and Y925), as well as the pan Rac1 and Cofilin, and their phosphorylated residues $\mathbf{h}-\mathbf{j}$. All of these proteins were resolved by immunoblotting technology and the GAPDH used as the housekeeping gene. In the images $\mathbf{k}-\mathbf{p}$, cells were challenged with $\mathrm{ZrO}_{2}$ enriched media and then evaluated for cytoskeletal rearrangement. Significances were considered when $* * p<0.0015 ; * * * p<0.0007$
In parallel, considering the direct effect of the zirconia on pre-osteoblast viability, we found a singular cell phenotype that stimulates cell proliferation, as $C D K 4$ gene was significant up-activated (Fig. 4a), while CDK2 (Fig. 4b) and CDK6 (Fig. 4c) remained unchanged, as well as $p 21$ (Fig. $4 d$ ), a well-documented gene suppressor. Thus, it is clear zirconia-based cell signaling promotes cell cycle progression in both the direct and indirect model.

\subsection{Zirconia stimulates a fine ECM remodeling- related protein processing}

To understand whether zirconia enriched medium affects ECM-remodeling, we investigated the capacity of challenged pre-osteoblast to process MMP-2, MMP-9, and their tissue inhibitors, TIMP1, TIMP2 and reversion-inducingcysteine-rich protein with kazal motifs (RECK). First, the $\mathrm{ZrO}_{2}$-enriched medium (indirect manner) caused a considerable ECM remodeling controlled by the challenged pre-osteoblast. Both MMPs-2 and -9 genes were significantly up-activated (Fig. 5a, b), while both TIMPs-1 and -2 genes were down-activated (Fig. 5c, d). Later, we measured the activity of the conditioned medium by challenged pre-osteoblast (Fig. 5e) and found an increase of their activities (Fig. 5f-k). In addition, a very similar profile was obtained on the machinery of ECM remodeling-related genes when cells were grown directly on the zirconia devices. Thus, Fig. 6a illustrates significant MMP-2 gene activation, while $M M P-9$ gene was unchanged (Fig. 6b). Importantly, MMP inhibitors TIMP-1 and RECK were up- 
a)

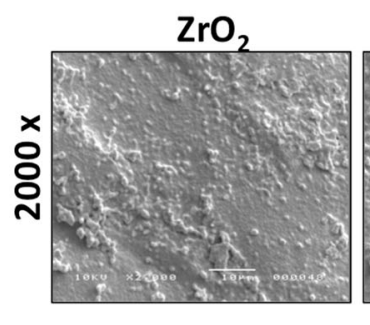

$\mathrm{ZrO}_{2}-$ Cells

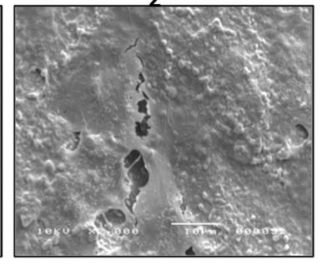

b)

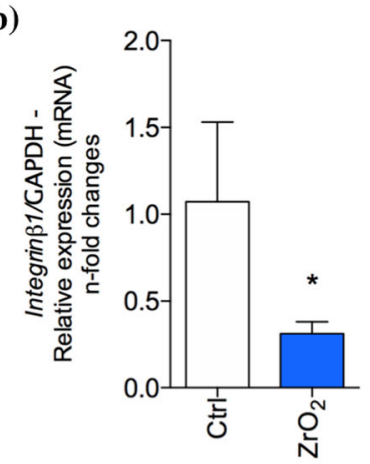

c)

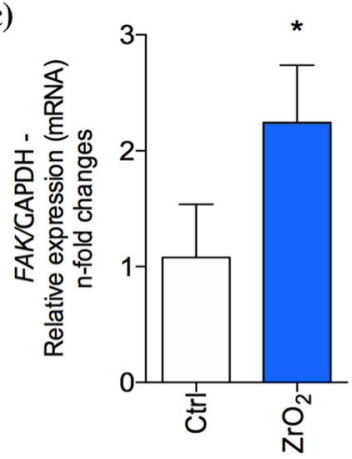

d)

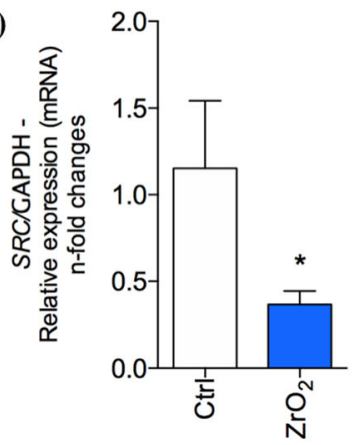

e)

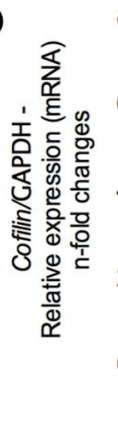

Fig. 2 Zirconia modulates the expression of adhesion genes and cytoskeletal rearrangement of pre-osteoblasts in direct contact. The electronmicrography (a) shows pre-osteoblast adhesion in direct contact with $\mathrm{ZrO}_{2}$ devices, where the cells are seeded on the disc up to $24 \mathrm{~h}$ and later evaluated by Scanning Electron Microscopy. The same

expressed (approximately 15-fold changes and 3.5-fold changes, respectively; Fig. 6c, d), while TIMP-2 remained unchanged (Fig. 6e)

\section{Discussion}

There is now a growing search for alternative methods to animal experimentation and also to understand the molecular mechanism involved with biomaterial response. Hence, we have been working to this end by exploring molecular pathways of the cell/biomaterial interaction responses to prioritize in vitro over in vivo tests. Many in vitro tests have indicated zirconia as a biocompatible material. However, it is necessary to understand the intracellular signaling responsible for governing its biological response, because Josset et al. [16] showed that zirconia surface allowed adhesion and spreading of human osteoblasts and the cells preserved their capacity to proliferate and differentiate. To address this issue, we investigated signaling pathways that govern crucial cell fates such as adhesion and proliferation by considering 2 biological models: an indirect, where the pre-osteoblasts were challenged with zirconia-enriched medium, and a direct, where the osteoblasts were grown directly on the zirconia
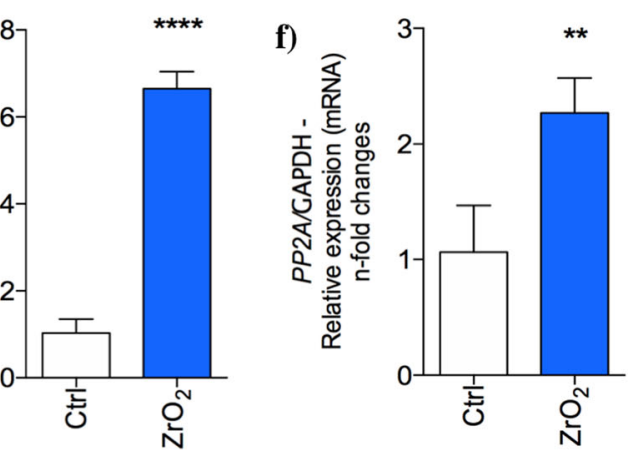

biological model was explored to collect the samples for the qPCR analysis, when previously the samples were harvested in TrizOL to evaluate an expression of adhesion and cytoskeleton rearrangementrelated genes $(\mathbf{b}-\mathbf{f})$. Significances were considered when ${ }^{*} p<0.02$, $* * p<0.0057$ and $* * * * p<0.0001$

surface. Our data strongly suggest zirconia interacts with the surrounding tissue, considering both direct and indirect model.

Previously, we considered Focal Adhesion Kinase (FAK) activation as a very interesting biomarker of cell adhesion upon integrin activation when interacting with substrates [17]. It is very known that FAK has three independent tyrosine-residues ( $\mathrm{Y}$ ) that undergo phosphorylations, which are classically related to cell adhesion, Y397, Y576/577, and Y925 [18, 19]. Mechanistically, the autophosphorylation at residue Y397 activates FAK and allows its interaction with $\mathrm{Src}$, a protein tyrosine kinase also involved with cell adhesion process and cell survival pathways $[20,21]$. Consequently, when phosphorylated at residue Y576/577, FAK initiates a cascade responsible for the rearrangement of the actin-based cytoskeleton [18, 22]. Lastly, the phosphorylation of the Y925 residue is related to adhesion, differentiation, and motile processes, among others by activating the MAPK pathway [23, 24]. In this work, the phosphorylation at Y397 site was decreased in response to $\mathrm{ZrO}_{2}$ enriched medium, but $\mathrm{Y} 576 / 577$ and Y925 sites remain unchanged. The phosphorylation at Y397 provoked FAK tridimensional changes providing interaction with $\mathrm{SH} 2$ domains as well as phosphorylation of residues Y576/577 and Y925 [20,25]. Thus, our results suggest 


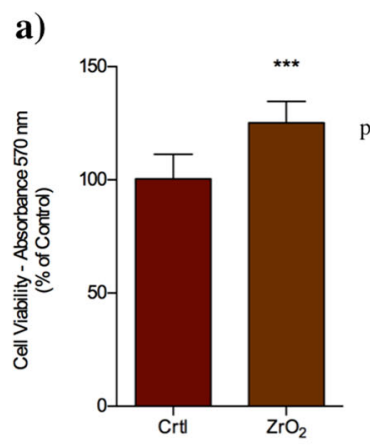

b)
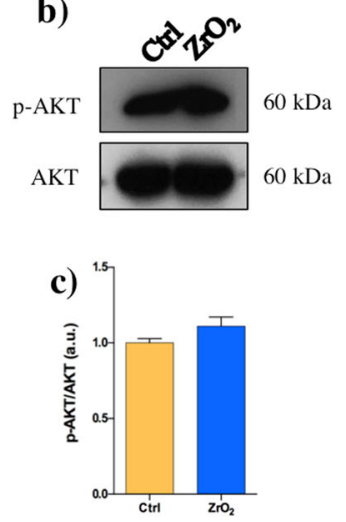

j)

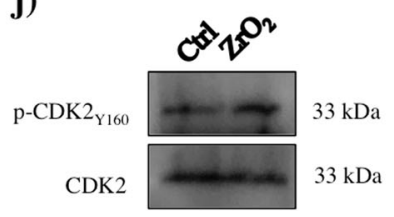

k)

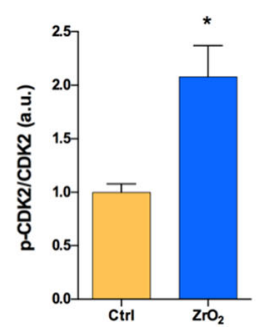

Fig. $3 \mathrm{ZrO}_{2}$ enriched medium modulates pre-osteoblast survival and proliferating processes. The effect on the pre-osteoblast viability was measured by classical MTT approach (a) and by revealing key proteins in these processes through immunoblotting, where we evaluated the phosphorylations of AKT (b-c) and a set of MAPKs (p38 and p-p38;

that the decrease of cell adhesion in response to $\mathrm{ZrO}_{2}$ enriched medium, proposed by the violet crystal approach, is related to the decrease of Y397 phosphorylation and this molecular mechanism could be a prerequisite to start cell proliferation.

In addition on this scenario, a decrease of Rac1 phosphorylation in response to $\mathrm{ZrO}_{2}$ enriched medium was also observed. Rac1, which is related to the cytoskeleton adaptations during the cellular attachment on substrate, migration, and adhesion process [26, 27], is regulated by FAK, Src, and others Rho GPTases members upstream [28]. The self-regulation of Rho GTPases is responsible, among others, for the formation and alteration of lamellipodial protrusion in the cell, and is very necessary during the cell migration process [28]. In conjunction, these signaling pathway can explain the different actin-related cytoskeleton rearrangement in response to zirconia, mainly because Rac1 also acts in the regulation of Cofilin [2], which is highly responsible for the reorganization of actin filaments during
MAPK

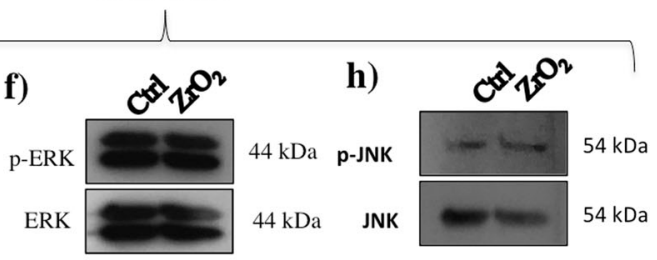

g)

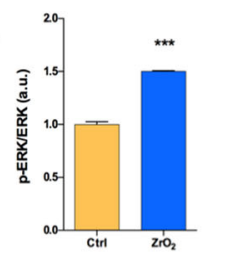

i)

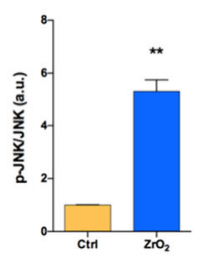

n)

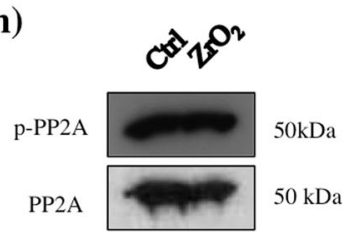

o)

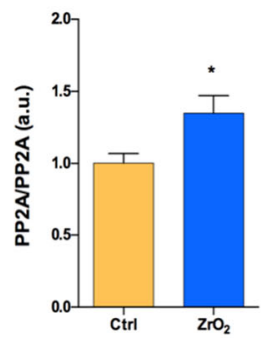

ERK and p-ERK; JNK and p-JNK) (d-i). The proliferation events were estimated by evaluating CDK2 and p15, as well as PP2A $(\mathbf{j}-\mathbf{- o})$ up to $24 \mathrm{~h}$ in response to $\mathrm{ZrO}_{2}$ enriched media. GAPDH was used as a housekeeping gene. Significances were considered when $* p<0.04$; $* * p<0.0057$

cell adhesion and spreading [29]. In agreement, our results found no significance in cofilin phosphorylation ( $\mathrm{S} 03)$ in response to $\mathrm{ZrO}_{2}$ enriched medium, when compared to the control group. This result can be reported both by the performance of other Rho GTPases [30], because Rac1 activation was decreased, as well as by the increased MAPKp38 phosphorylation, observed in response to $\mathrm{ZrO}_{2}$ enriched medium.

In this scenario, we also investigated the Ser/Thr phosphatase $2 \mathrm{~A}$ (PP2A). When phosphorylated by Src at its Y307 residue, PP2A is inactivated by decreasing its activity in hydrolyzing phospho-serine and phospho-threonine residues [31]. This may be an explanation for the increased phosphorylation of P38 [32], in turn for the compensation mechanism for phosphorylation of Cofilin, since the residue S03 remains phosphorylated [33]. Combining these results, it is possible to suggest an extensive performance of Src in the mechanisms of adhesion and survival of cells in contact with zirconia surface. The 

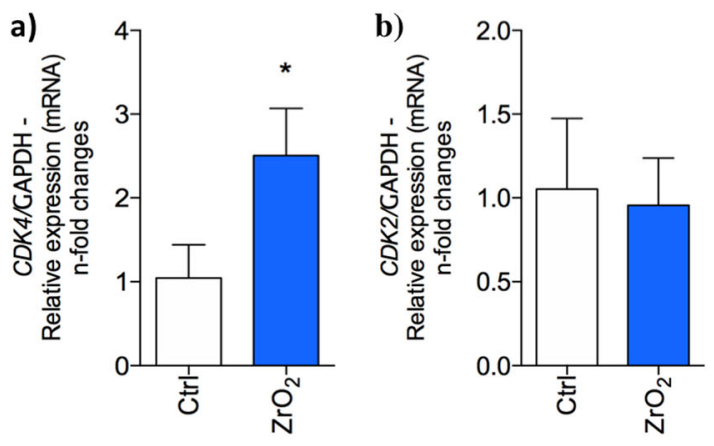

Fig. 4 Zirconia modulates directly pre-osteoblast cell cycle. Previously the cells were marinated up to $24 \mathrm{~h}$ directly in contact with zirconia, when the RNA was extracted and provided condition for cDNA
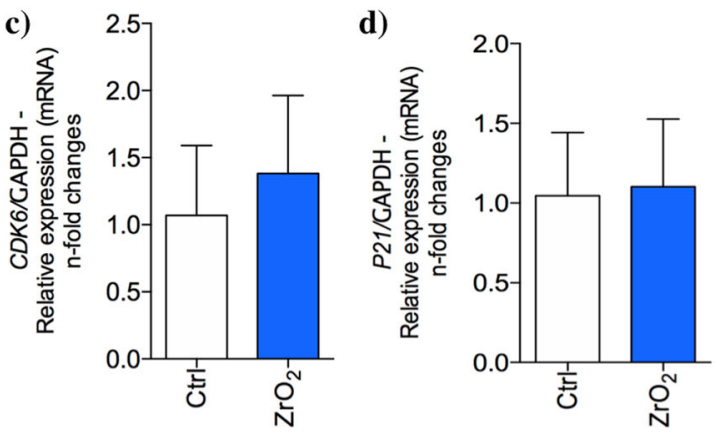

synthesis. We evaluated the expression profile of the CDK-2, CDK-4, and CDK-6 (a-c) and p21 (d), all of them related with cell cycle progression. Significances were considered when $* p<0.05$ a)

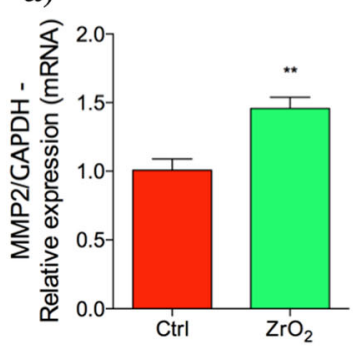

b)

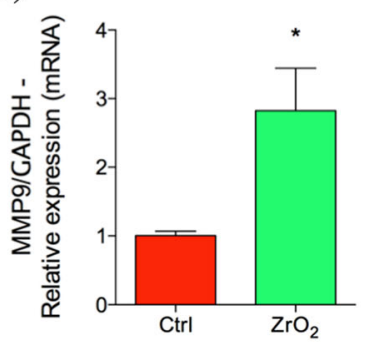

c)

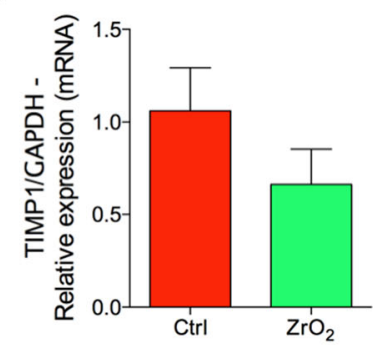

d)

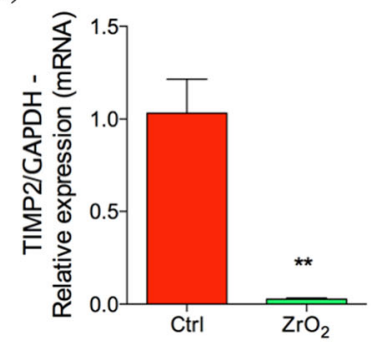

e)

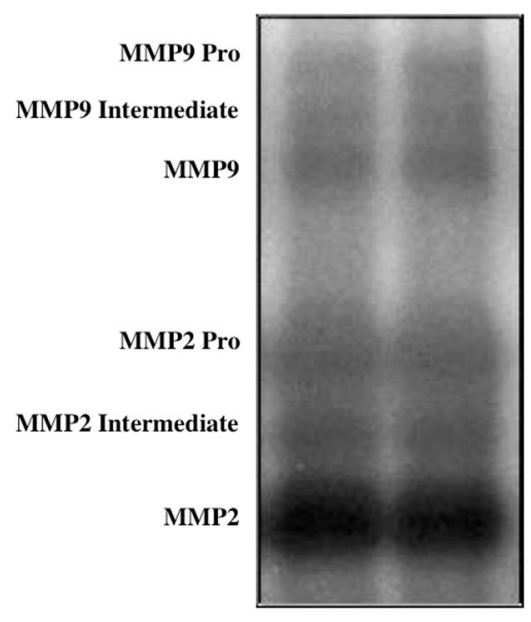

$92 \mathrm{kDa}$

f)

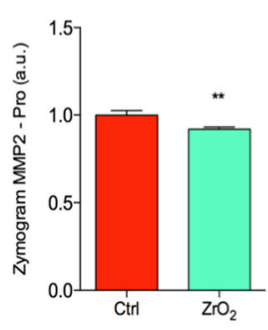

$72 \mathrm{kDa} \quad$ i)

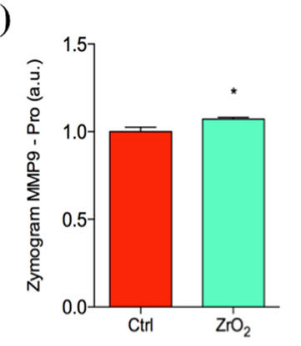

g)

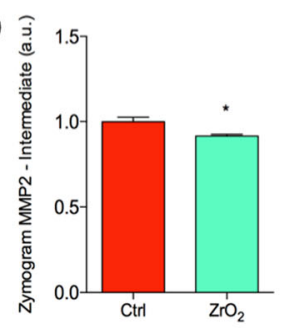

j)

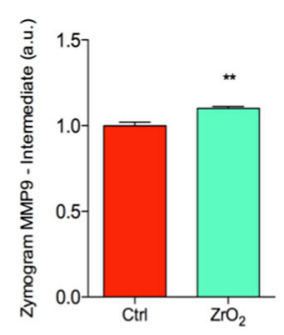

h)

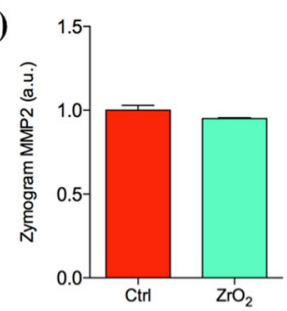

k)

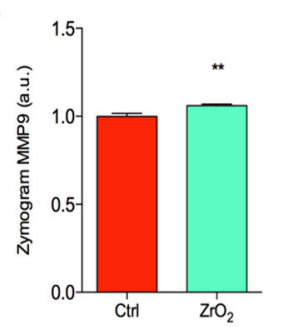

Fig. 5 MMPs molecular processing in response to $\mathrm{ZrO}_{2}$ enriched medium. Here we evaluated the expression profile of MMP2 and MMP9 (a-b) and their tissue inhibitors (TIMPs): TIMP1 and TIMP2 (c-d). In addition, MMPs activities were measured by the

involvement of other members of the Rho GTPase family (such as ROCK1, RhoA, RhoC, among others) may also explain the adhesion mechanisms in response to zirconia [34].

Additionally, we also reported an increase of MTT result by pre-osteoblast in response to $\mathrm{ZrO}_{2}$ enriched medium
Zymography technology (e) and the analysis of those activities of both MMP9 and MMP2 are presented $(\mathbf{f}-\mathbf{k})$. Significances were considered when $* p<0.02$ and $* * p<0.0027$

when compared to control. This can be interpreted as an increase in the energy demand of cells, by increasing the demand of dehydrogenases, or enhancing the number of cells as the $\mathrm{ZrO}_{2}$ enriched medium stimulates pre-osteoblast proliferation. To identify whether this treatment interferes in cell cycle progression as suggested earlier, we decided to 
Fig. 6 MMPs genes are reprogrammed in response directly to Zirconia. The biological model was explored by seeding the cells directly on the zirconia discs and after $24 \mathrm{~h}$ the RNA was extracted. To estimate the ECM remodelingrelated genes, we evaluated the expression profile of MMP2 and MMP9 (a-b) and their tissue inhibitors: TIMPs and RECK (c-e). Significances were considered when $* * * p<0.0007$ and $* * * * p<0.0001$
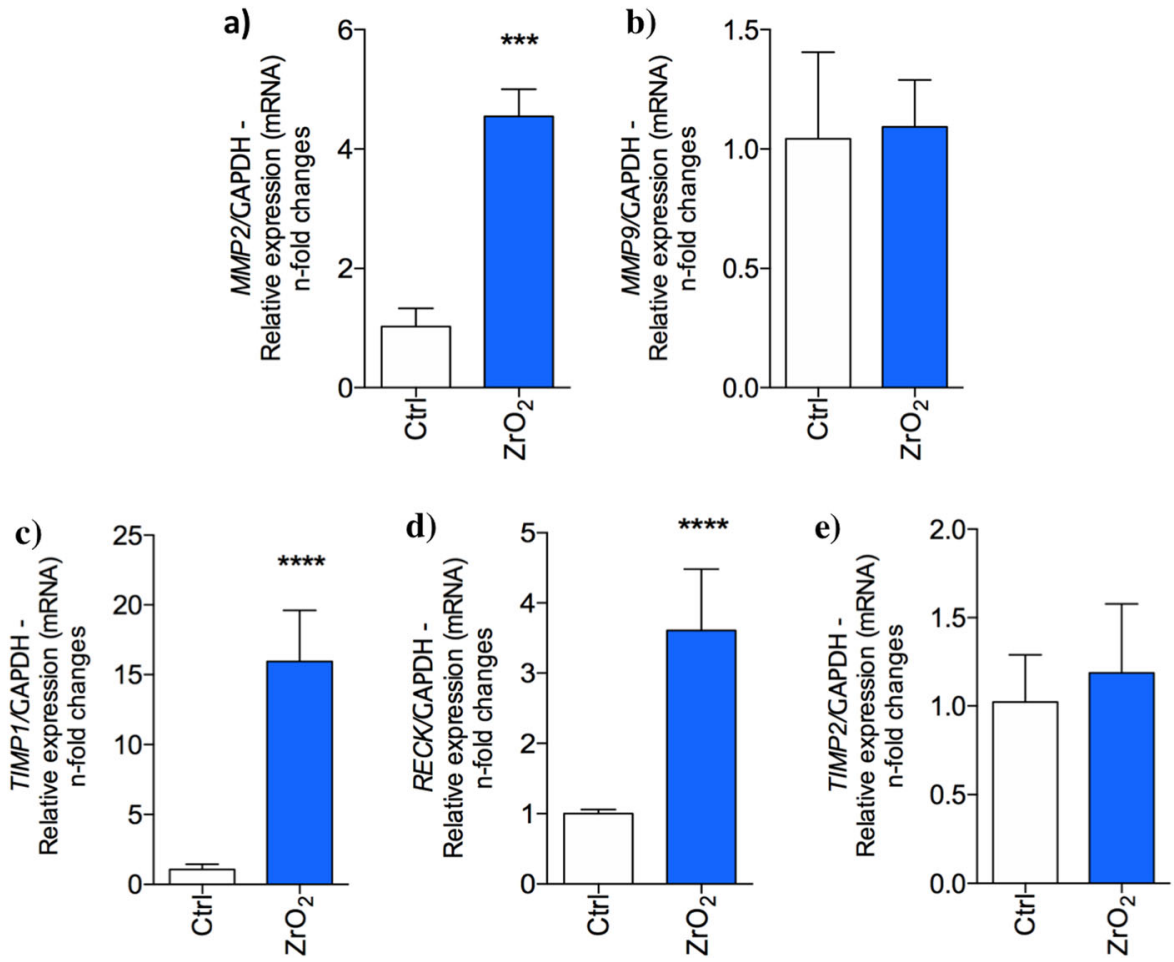

investigate CDK2 and p15. The significant upphosphorylation of CDK2 (Y160) suggests its involvement in progressing the cell cycle [35, 36]. On the other hand, the expression of $\mathrm{p} 15$, a cellular inhibitor for CDK2, remained unchanged in response to $\mathrm{ZrO}_{2}$ enriched medium, obviously evidencing the greater involvement of CDK2 in mechanisms of cell cycle modulation.

Later, to see whether $\mathrm{ZrO}_{2}$ enriched medium could interfere in ECM remodeling, we investigated the balance of MMPs and their inhibitors. In our cell culture model, we observed $M M P-2$ and -9 expression by qPCR technology and the presence of pro-MMP-2 gelatinolytic activity by zymography. TIMP2 expression was reduced while $M M P 2$ and $M M P 9$ expressions significantly increased and this balance is in agreement, since TIMP2 is a metalloproteinase inhibitor [13]. Additionally, the expression of $M M P 9$ by qPCR was found to be highly significant in response to $\mathrm{ZrO}_{2}$ enriched medium. MMP9 seems to play an important and functional role for pre-osteoblast behavior in response to $\mathrm{ZrO}_{2}$ enriched medium, because its activity also significantly increased while MMP2 activity decreased. Our results are consistent with other works that demonstrated the influence of this biomaterial on MMP production in osteoblasts [37, 38]. These data are in agreement with results provided by in vitro and in vivo experiments and suggest that MMPs and TIMPs produced by bone cells are important in the balance between bone formation and resorption.
The down-regulation of MMP2 could explain the low phosphorylation of FAK at residue Y379, found in the response to $\mathrm{ZrO}_{2}$ enriched medium, since the activation of the FAK / Src / PI3K / AKT pathway is required for remodeling of the extracellular medium by MMP2 action $[39,40]$. Another hypothesis for low MMP2 activity would be a low production of collagen by the cell [41]. The interactions between osteoblasts and biomaterials, such as zirconia, alter both MMP-2, -9 and TIMP-1 expression indicating that biomaterials may influence bone remodelingrequired integration of biomedical devices.

Altogether, our results showed for the first time the molecular mechanisms triggered by zirconia on preosteoblasts. Specifically, our results showed that there is a stimulus for ECM remodeling as a prerequisite to promote cell cycle progression by finely orchestrating multisite FAK phophorylations and culminating in cytoskeleton rearrangement. In addition, our proposal is able to recognize mechanisms involved with cell/biomaterial interaction, promoting a necessary stage of refinement of technologies used during new biomaterial development, consequently reducing the animal experimentation during the process, which is absolutely in accordance with the $3 \mathrm{R}$ 's principle proposed as an international ethical parameter for animal experimentation.

Acknowledgements The authors are grateful to Fundação de Amparo a Pesquisa do Estado de São Paulo (FAPESP) for the financial support (grants: \#2015/03639-8, 2016/08888-9, 2014/22689-3). 


\section{Compliance with ethical standards}

Conflict of interest The authors declare that they have no conflict ofinterest.

\section{References}

1. van der Eerden BCJ, Teti A, Zambuzzi WF. Bone, a dynamic and integrating tissue. Arch Biochem Biophys. 2014;561:1-2.

2. Zambuzzi WF, Ferreira CV, Granjeiro JM, Aoyama H. Biological behavior of pre-osteoblasts on natural hydroxyapatite: a study of signaling molecules from attachment to differentiation. J Biomed Mater Res A. 2011;97:193-200.

3. Coelho PG, Jimbo R. Osseointegration of metallic devices: current trends based on implant hardware design. Arch Biochem Biophys. 2014;561:99-108.

4. Bezerra F, Ferreira MR, Fontes GN, da Costa Fernandes CJ, Andia DC, Cruz NC, et al. Nano hydroxyapatite-blasted titanium surface affects pre-osteoblast morphology by modulating critical intracellular pathways. Biotechnol Bioeng. 2017;114:1888-98.

5. Pasold J, Markhoff J, Tillmann J, Krogull M, Pisowocki P, Bader R. Direct influence of titanium and zirconia particles on the morphology and functionality of mature human osteoclasts. J Biomed Mater Res A. 2017;105:2608-15.

6. Parmigiani-Izquierdo JM, Cabaña-Muñoz ME, Merino JJ, Sánchez-Pérez A. Zirconia implants and peek restorations for the replacement of upper molars. Int J Implant Dent. 2017;3:5.

7. Hafezeqoran A, Koodaryan R. Effect of Zirconia dental implant surfaces on bone integration: a systematic review and metaanalysis. Biomed Res Int. 2017;2017:9246721.

8. Gautam C, Joyner J, Gautam A, Rao J, Vajtai R. Zirconia based dental ceramics: structure, mechanical properties, biocompatibility and applications. Dalt Trans R Soc Chem. 2016;45:19194-215.

9. Cionca N, Hashim D, Mombelli A. Zirconia dental implants: where are we now, and where are we heading? Periodontol 2000. 2017;73:241-58.

10. Gapski R, Martinez EF. Behavior of MC3T3-E1 osteoblastic cells cultured on titanium and zirconia surfaces. Implant Dent. 2017;26:1-377.

11. Mosmann T. Rapid colorimetric assay for cellular growth and survival: application to proliferation and cytotoxicity assays. J Immunol Methods Neth. 1983;65:55-63.

12. LOWRY OH, ROSEBROUGH NJ, FARR AL, RANDALL RJ. Protein measurement with the Folin phenol reagent. J Biol Chem U S. 1951;193:265-75.

13. Zambuzzi WF, Yano CL, Cavagis ADM, Peppelenbosch MP, Granjeiro JM, Ferreira CV. Ascorbate-induced osteoblast differentiation recruits distinct MMP-inhibitors: RECK and TIMP-2. Mol Cell Biochem Neth. 2009;322:143-50.

14. Lefebvre V, Peeters-Joris C, Vaes G. Production of gelatindegrading matrix metalloproteinases ('type IV collagenases') and inhibitors by articular chondrocytes during their dedifferentiation by serial subcultures and under stimulation by interleukin- 1 and tumor necrosis factor alpha. Biochim Biophys Acta Neth. 1991;1094:8-18.

15. Ferreira CF, Carriel Gomes MC, Filho JS, Granjeiro JM, Oliveira Simoes CM, Magini R de S. Platelet-rich plasma influence on human osteoblasts growth. Clin Oral Implants Res Den. 2005; 16:456-60.

16. Josset Y, Oum'Hamed Z, Zarrinpour A, Lorenzato M, Adnet JJ, Laurent-Maquin D. In vitro reactions of human osteoblasts in culture with zirconia and alumina ceramics. J Biomed Mater Res U S. 1999;47:481-93.
17. Zambuzzi WF, Bruni-Cardoso A, Granjeiro JM, Peppelenbosch MP, de Carvalho HF, Aoyama $\mathrm{H}$, et al. On the road to understanding of the osteoblast adhesion: cytoskeleton organization is rearranged by distinct signaling pathways. J Cell Biochem U S. 2009;108:134-44.

18. Cavagis A, Takamori E, Granjeiro J, Oliveira R, Ferreira C, Peppelenbosch M, et al. TNFalpha contributes for attenuating both Y397FAK and Y416Src phosphorylations in osteoblasts. Oral Dis Den. 2014;20:780-6.

19. Fang X-Q, Liu X-F, Yao L, Chen C-Q, Lin J-F, Gu Z-D, et al. Focal adhesion kinase regulates the phosphorylation protein tyrosine phosphatase-alpha at Tyr789 in breast cancer cells. Mol Med Rep Greece. 2015;11:4303-8.

20. Thiyagarajan V, Lin S, Chia Y, Weng C. Biochimica et Biophysica Acta the autophosphorylation site of focal adhesion kinase (Y397) by molecular docking. BBA - Gen Subj Elsevier B V. 2013;1830:4091-101.

21. Dixon RDS, Chen Y, Ding F, Khare SD, Prutzman KC, Schaller MD et al. New Insights into FAK signaling and localization based on detection of a FAT domain folding intermediate. Chapel Hill: University of North Carolina; 2004;12:2161-71.

22. Blangy A, Touaitahuata H, Cres G, Pawlak G. Cofilin activation during podosome belt formation in osteoclasts. PLoS One. 2012;7:e45909.

23. Mitra SK, Mikolon D, Molina JE, Hsia DA, Hanson DA, Chi A, et al. Intrinsic FAK activity and Y925 phosphorylation facilitate an angiogenic switch in tumors. Oncogene. 2006;25:5969-84.

24. da Costa Fernandes CJ, do Nascimento AS, da Silva RA, Zambuzzi WF. Fibroblast contributes for osteoblastic phenotype in a MAPK-ERK and sonic hedgehog signaling-independent manner. Mol Cell Biochem. 2017;436:111-7.

25. Fang X, Liu X, Yao L, Chen C, Lin J, Ni P, et al. New insights into FAK phosphorylation based on a FAT domain-defective mutation. PloS One. 2014;9:1-10.

26. Wolfenson H, Lavelin I, Geiger B. Dynamic regulation of the structure and functions of integrin adhesions. Dev Cell. 2013;24:447-58.

27. Wehrle-Haller B, Imhof BA. The inner lives of focal adhesions. Trends Cell Biol. 2002;12:382-9.

28. Parsons JT, Horwitz AR, Schwartz MA. Cell adhesion: integrating cytoskeletal dynamics and cellular tension. Nat Rev Mol Cell Biol Engl. 2010;11:633-43.

29. Kueh HY, Brieher WM, Mitchison TJ. Dynamic stabilization of actin filaments. Proc Natl Acad Sci U S A U S. 2008;105:16531-6.

30. Martín-Villar E, Borda-d'Agua B, Carrasco-Ramirez P, Renart J, Parsons M, Quintanilla M, et al. Podoplanin mediates ECM degradation by squamous carcinoma cells through control of invadopodia stability. Oncogene. 2015;34:4531-44.

31. Barisic S, Schmidt C, Walczak H, Kulms D. Tyrosine phosphatase inhibition triggers sustained canonical serine-dependent $\mathrm{NFKB}$ activation via Src-dependent blockade of PP2A. Biochem Pharmacol. 2010;80:439-47.

32. Avdi NJ, Malcolm KC, Nick JA, Worthen GS. A role for protein phosphatase-2A in p38 mitogen-activated protein kinase-mediated regulation of the c-Jun NH2-terminal kinase pathway in human neutrophils. J Biol Chem. 2002;277:40687-96.

33. Oleinik NV, Krupenko NI, Krupenko SA. ALDH1L1 inhibits cell motility via dephosphorylation of cofilin by PP1 and PP2A. Oncogene Engl. 2010;29:6233-44.

34. Bertazzo S, Zambuzzi WF, Campos DDP, Ferreira CV, Bertran CA. A simple method for enhancing cell adhesion to hydroxyapatite surface. Clin Oral Implants Res Den. 2010;21:1411-3.

35. Hughes BT, Sidorova J, Swanger J, Monnat RJ, Clurman BE. Essential role for $\mathrm{Cdk} 2$ inhibitory phosphorylation during 
replication stress revealed by a human Cdk2 knockin mutation. Proc Natl Acad Sci. 2013;110:8954-9.

36. Ayaydin F, Vissi E, Mészáros T, Miskolczi P, Kovács I, Fehér A, et al. Inhibition of serine/threonine-specific protein phosphatases causes premature activation of cdc2 MsF kinase at G2/M transition and early mitotic microtubule organisation in alfalfa. Plant J. 2000;23:85-96.

37. Haynes DR, Hay SJ, Rogers SD, Ohta S, Howie DW, Graves SE. Regulation of bone cells by particle-activated mononuclear phagocytes. J Bone Jt Surg Br Engl. 1997;79:988-94.

38. Panagakos FS, Kumar S. Differentiation of human osteoblastic cells in culture: modulation of proteases by extracellular matrix and tumor necrosis factor-alpha. Inflammation. $\mathrm{U} S$. 1995;19:423-43.
39. Wang R, Wang W, Ao L, Wang Z, Hao X, Zhang H. Benzo[a] pyrene-7,8-diol-9,10-epoxide suppresses the migration and invasion of human extravillous trophoblast HTR-8/SVneo cells by down-regulating MMP2 through inhibition of FAK/SRC/PI3K/ AKT pathway. Toxicol Elsevier. 2017;386:72-83.

40. Dang D, Bamburg JR, Ramos DM. ??v??3integrin and cofilin modulate K1735 melanoma cell invasion. Exp Cell Res. 2006;312:468-77.

41. Oum'hamed Z, Garnotel R, Josset Y, Trenteseaux C, LaurentMaquin D. Matrix metalloproteinases MMP-2, -9 and tissue inhibitors TIMP-1, -2 expression and secretion by primary human osteoblast cells in response to titanium, zirconia, and alumina ceramics. J Biomed Mater Res. 2004;68:114-22. 